\title{
Computer simulations in the ventilation network of the Vulcan Mine
}

\author{
Corneliu Boantăa ${ }^{*}$, and Cristian Tomescu \\ ${ }^{1}$ National Institute for Research and Development in Mine Safety and Protection to Explosion - \\ INCD INSEMEX Petroșani , Romania
}

\begin{abstract}
Maintaining safety and health conditions underground, especially where potentially explosive atmospheres are possible, depends mainly on how the ventilation system is built, applied and operated in the ventilation network. The ventilation networks of a mining unit for the exploitation of the useful mineral substance are mining works that aim to ensure optimal microclimate conditions in the underground. An ventilation network is built of nodes and branches, in order to establish its structure. In order to establish the optimal air flows at branch level, specialized programs are used, with the help of which the modeling, solving and optimization of the ventilation networks can be performed. Optimizing the management of the ventilation system involves in-depth and complex analyzes on the ventilation network that require a huge volume of data that can be processed only with the help of computing technology. The paper presents an analysis of the ventilation network of the Vulcan mine using the calculation technique to simulate situations that may occur in the ventilation system.
\end{abstract}

\section{Introduction}

The optimal management of the ventilation system at the level of a mining unit involves the use of computer technology in order to perform relevant analyzes as well as to successfully prevent the occurrence of dangerous situations. The forecast of the changes that can occur in the ventilation network based on possible hypotheses can be made by simulating them with the help of specialized software in the solved network of the mining unit. $[9,10]$

\section{Overview}

In order to obtain the optimal working conditions underground, the primary protection must be ensured, namely the achievement of ventilation. Ventilation of mining works aims to achieve three main objectives:[6,11]

- ensuring the oxygen concentration, necessary for the existing personnel in the underground;

- dilution of existing explosive and / or toxic gases in the mining network

\footnotetext{
* Corresponding author: cornel.boanta@insemex.ro
} 
- taking over the heat released in the mining network, due to both human activity and the geothermal gradient;

In order to achieve a good ventilation at the level of each mining work, it is necessary to optimize the distribution of air flows on each branch of the ventilation network. In this sense, it is necessary to solve the ventilation network at the level of a mine. An example of a complex ventilation network is that belonging to the Vulcan mine. $[1,7,8]$

\section{Presentation of the Vulcan mine ventilation network}

The ventilation network for the Vulcan mine was extremely complex. Currently, due to subjective causes such as special events - explosions, or objective causes such as depletion of the supply of useful minerals, it is more limited.[5] Thus, the ventilation network includes four wells: Chorin Well, Schip Well, Prokop Well and X - Valea Arsului Well. It also includes three ventilation suites with the related ventilation stations, namely (Suitor B'Allomaş, suitor Karollus and suitor Ionaşcu), at the same time it also includes underground mining works arranged at the level of four horizons (horizon 315; horizon.360; oriz.420; oriz.480). These works consist of main transverse galleries, directional galleries, diagonal galleries, transverse number galleries, inclined planes, abatements, connecting suites. The entire ventilation network comprises 251 junctions (nodes) and 300 branches [2].

\section{Solving the mine ventilation network}

The method of successive Hardy Cross approximations was used to solve such a complex ventilation network. This method is the basis of a specialized computer program CANVENT designed in Canada $[3,4]$. With the help of this specialized software it was possible to obtain the solution of the ventilation network as well as the optimization of the distribution of the air flows at the level of branches. .

The solution of the ventilation network related to the Vulcan mine will require certain steps, namely:

a). Marking on the spatial ventilation scheme of the junctions (nodes) related to the ventilation network;

b). Collection of geodetic coordinates for the identified junctions;

c). Entering the geodetic coordinates specific to the junctions as well as the existing branches, in the software database;

d). Carrying out specialized in situ measurements that include:

- measurements regarding the aerodynamic parameters of the mining works;

- $\quad$ measurements regarding the geometric parameters of the mining works;

- measurements on the physical parameters of the air .

e). Calculation of the aerodynamic resistances specific to each branch;

f). Entering the values of the parameters specific to the ventilation network, in the database of the specialized program CANVENT;

g). Representation of the ventilation network, which can be done in $2 \mathrm{D}$ or $3 \mathrm{D}$ system;

h). Balancing the ventilation network;

i). Solving the ventilation network. This stage identifies the meaning and the optimal distribution of the air flows on each branch;

j). Getting results.

In this final stage, the data on the graphical solution of the ventilation network are available on electronic or paper support. 


\section{Simulations performed in the ventilation network}

The CANVENT program for solving the ventilation networks allows the simulation of some changes that can occur in the ventilation network. Thus in the ventilation network from E.M. Vulcan the following situations were simulated:

\subsection{Elimination from the current ventilation network of the defective air exhaust circuit from no. 4/3 / VI to the suite Terezia;}

Modeling no. 1 - the elimination from the current ventilation network of the air exhaust circuit from the frontal face with undermined bench no. 4 str. $3 \mathrm{bl}$. VI to the suite Terezia (branch 360 - 420)

In order to carry out this modeling, insulation constructions were placed on the connecting gallery no. 3 bl. VI, branch 100-101, respectively on the suite no. 4 bed, branch 92-93.

By locating these insulation constructions, the following branches were removed from the ventilation network: 92-93; 93-94; 94-95; 95-96; 96-97; 97-98; 98-99; 99-100 and 100-101, respectively.

Following the closure of this route of mining works and for the maintenance of the flow provided for in face no. 2 str. $3 \mathrm{bl}$. VI the door with register on the transversal gallery oriz was abolished. 420 (branch 75-101).

The changes made in this modeling are shown in fig. 1.

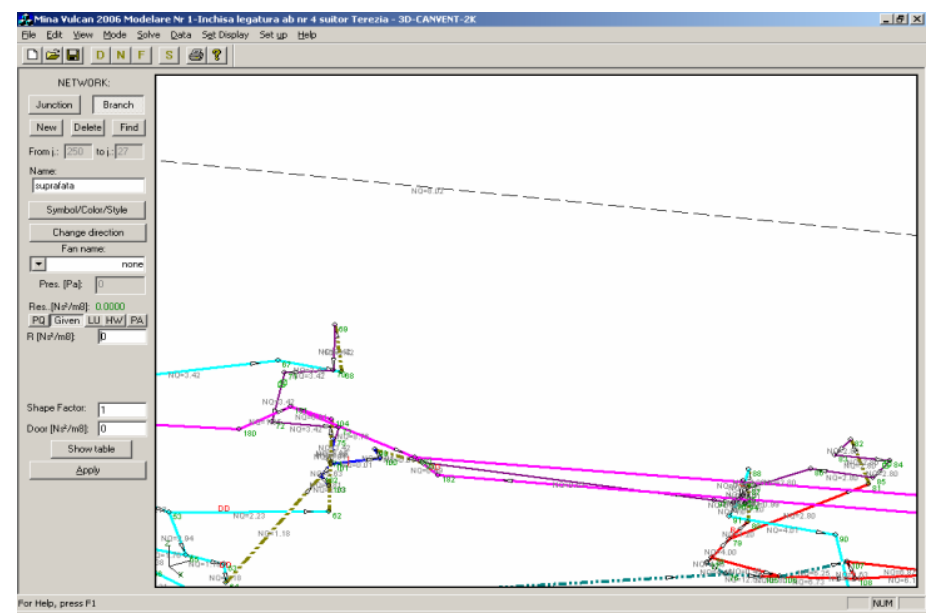

Fig. 1 Modeling no. 1

Compared to the current situation, the following results were obtained:

- The air flow on the fresh air supply circuit at the horizon level. 360, branches 22-23; 15-24; $30-31$; 193-194 increased from $33.91 \mathrm{~m} 3$ / s to $34.54 \mathrm{~m} 3$ / s (from $2035 \mathrm{~m} 3$ / min to $2073 \mathrm{~m} 3$ / $\mathrm{min})$.

- Air flow at the level of the front abattoir with undermined coal bench no. 2 str. 3 bl. VI was insignificantly modified.

- The air flow on the inclined plane of ventilation 360 - 315 increased from $16.03 \mathrm{~m} 3 / \mathrm{s}$ to $16.98 \mathrm{~m} 3$ / s (from $962 \mathrm{~m} 3 / \mathrm{min}$ to $1019 \mathrm{~m} 3 / \mathrm{min}$ ).

- The air flow at the level of the front abattoir with undermined coal bench no. 4 pp. 3 pp. VI increased from $2.1 \mathrm{~m} 3 / \mathrm{s}$ to $2.8 \mathrm{~m} 3 / \mathrm{s}$.

- Air flow at the level of face no. 0 page 3 bl. VIII elevation $376 \mathrm{~m}$ respectively no. 0 str. 3 bl. VIII elevation $386 \mathrm{~m}$ have changed insignificantly. 
- On the exhaust circuit of the exhaust air afferent to the face no. 2 str. 3 bl. VI (branch 181183 ) at the horizon level. 480, the air flow increased from $8.19 \mathrm{~m} 3 / \mathrm{s}$ to $8.76 \mathrm{~m} 3 / \mathrm{s}$ (approximately $34 \mathrm{~m} 3 / \mathrm{min}$ ).

- On the exhaust circuit of the exhaust air afferent to the face no. 4 str. 3 bl. VI (branch 9089), air flow at the horizon level. 360 decreased from $5.18 \mathrm{~m} 3 / \mathrm{s}$ to $4.01 \mathrm{~m} 3 / \mathrm{s}$ (approximately $70 \mathrm{~m} 3 / \mathrm{min}$ ).

- On the face evacuation circuit no. 0 page $3 \mathrm{bl}$. VIII elevation $376 \mathrm{~m}$, respectively no. 0 str. 3 bl. VIII elevation $386 \mathrm{~m}$, (branches 249-208; 152-153) the air flows have changed insignificantly.

- At the mine level (branches 240-242 and 235-237 respectively) the flows remained practically the same.

\subsection{The situation in the case of the chip silo is empty and the door in the silo- chip connection gallery (at the top of the silo) is open respectively the horizontal silo collector.360 is full;}

Modeling no. 2 - The situation in which the silo from the silo is empty and the door from the silochip connection gallery (at the top of the silo) is open, respectively the collector silo oriz. 360 is full.

In order to perform this modeling, it was considered that the circuit between the evacuation of the face no. 4 pp. 3 pp. VI oriz. 360 and the cross gallery gallery Terezia oriz. 420 was closed, ie modeling no. 2 had as starting point the modeling no. 1.

Also, the door on the skip connection gallery was removed - the upper part of the silo level 387 $\mathrm{m}$ (branch 8-15) the initial resistance of $5 \mathrm{Ns} 2 / \mathrm{m} 8$ was removed from the collector silo branch 14-15 thus simulating the empty silo. At the same time, the resistance on the rice collecting silo increased. 360 (branch 46-48), thus simulating the full silo.

The changes made in this modeling are shown in fig. 2.

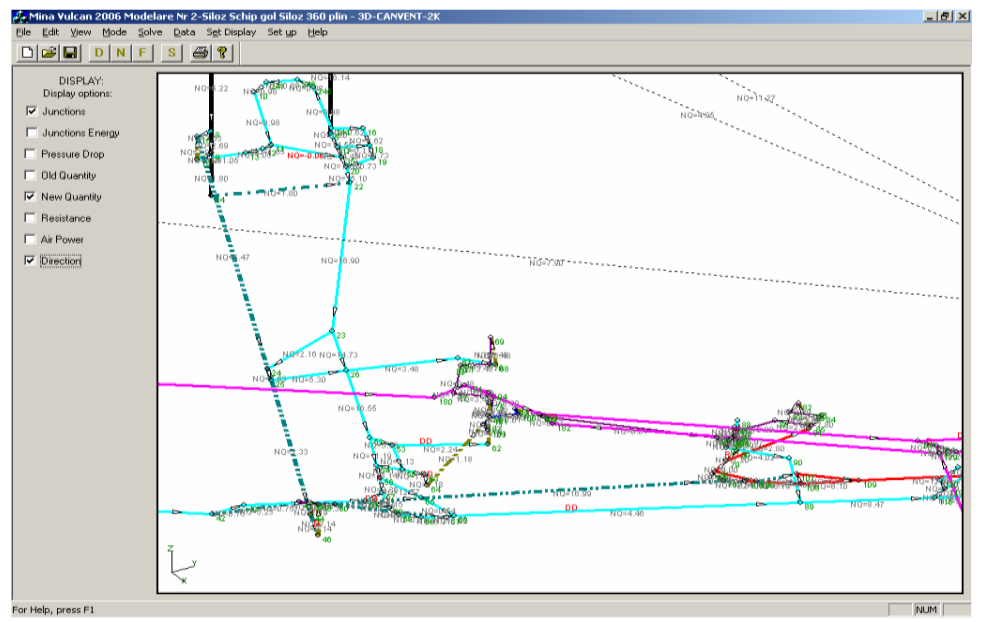

Fig. 2 Modeling no. 2

Compared to the current situation, the following results were obtained:

- The air flow on the fresh air supply circuit at the horizon level. 360, branches 22-23; 15-24; $30-31$; 193-194 increased from $33.91 \mathrm{~m} 3 / \mathrm{s}$ to $34.65 \mathrm{~m} 3 / \mathrm{s}$.

- The air flow at the level of the front abattoir with undermined coal bench no. 2 str. 3 bl. VI was insignificantly modified.

- The air flow on the inclined ventilation plane 360 - 315 increased from 16.03 $\mathrm{m} 3 / \mathrm{s}$ to $17 \mathrm{~m} 3 / \mathrm{s}$. 
- The air flow at the level of the front abattoir with undermined coal bench no. 4 pp. 3 pp. VI increased from $2.1 \mathrm{~m} 3 / \mathrm{s}$ to $2.8 \mathrm{~m} 3 / \mathrm{s}$.

- Air flow at the level of face no. 0 page $3 \mathrm{bl}$. VIII elevation $376 \mathrm{~m}$ respectively no. 0 str. 3 bl. VIII elevation $386 \mathrm{~m}$ have changed insignificantly.

- On the exhaust circuit of the exhaust air afferent to the face no. 2 str. 3 bl. VI (branch 181183) at the horizon level. 480, the air flow increased from $8.19 \mathrm{~m} 3 / \mathrm{s}$ to $8.80 \mathrm{~m} 3 / \mathrm{s}$.

- On the exhaust circuit of the exhaust air afferent to the face no. 4 str. 3 bl. VI (branch 90 89), air flow at the horizon level. 360 decreased from $5.18 \mathrm{~m} 3 / \mathrm{s}$ to $4.03 \mathrm{~m} 3 / \mathrm{s}$.

- On the face evacuation circuit no. 0 page $3 \mathrm{bl}$. VIII elevation $376 \mathrm{~m}$, respectively no. 0 str. 3 bl. VIII elevation $386 \mathrm{~m}$, (branches 249-208; 152-153) the air flows have changed insignificantly.

- At the mine level (branches 240-242 and 235-237 respectively) the flows remained practically the same.

\subsection{The situation in which the chip silo is full and the door in the silo-chip connection gallery (at the top of the silo) is closed, respectively the horizontal silo collector.360 is empty;}

Modeling no. 3 - the situation in which the chip silo is full and the door in the silo-chip connection gallery (at the top of the silo) is closed, respectively the rice collector silo. 360 is empty.

Within this modeling, it was considered that the circuit between the evacuation of the face no. 4 pp. 3 pp. VI oriz. 360 and the cross gallery gallery Terezia oriz. 420 was closed, ie modeling no. 3 has as starting point the modeling no. 1.

The strength of the rice collector silo has also been reduced. 360 , thus simulating the situation of empty silo. At the same time, the resistance of the silo from the chip was increased in order to simulate the situation of the full silo.

The changes made in this modeling are shown in fig. 3 .

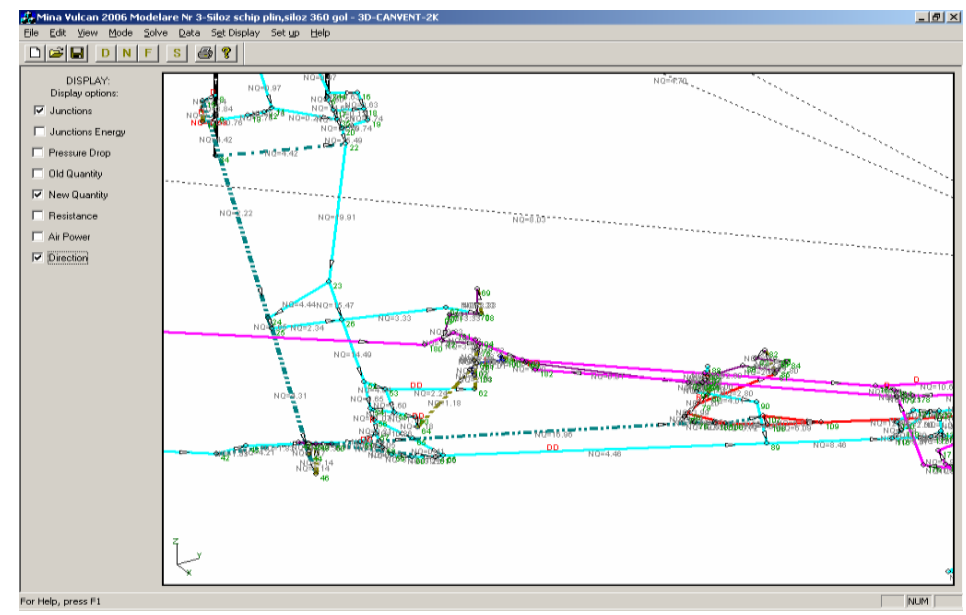

Fig. 3 Modeling no. 3

Compared to the current situation, the following results were obtained:

- The air flow on the fresh air supply circuit at the horizon level. 360, branches 22-23; 15-24;

$30-31$; 193-194 increased from $33.91 \mathrm{~m} 3 / \mathrm{s}$ to $34.46 \mathrm{~m} 3 / \mathrm{s}$.

- The air flow on the connecting suite (branch 25-44) increased from $1.8 \mathrm{~m} 3$ / s to $4.31 \mathrm{~m} 3$ / s.

- The air flow at the level of the front abattoir with undermined coal bench no. 2 str. 3 bl. VI was insignificantly modified. 
- The air flow on the inclined ventilation plane 360 - 315 increased from $16.03 \mathrm{~m} 3$ / s to 16.97 $\mathrm{m} 3 / \mathrm{s}$.

- The air flow at the level of the front abattoir with undermined coal bench no. 4 page $3 \mathrm{bl}$. VI increased from $2.1 \mathrm{~m} 3 / \mathrm{s}$ to $2.8 \mathrm{~m} 3 / \mathrm{s}$.

- Air flow at the level of face no. 0 page 3 bl. VIII elevation $376 \mathrm{~m}$ respectively no. 0 str. 3 bl. VIII elevation $386 \mathrm{~m}$ have changed insignificantly.

- On the exhaust circuit of the exhaust air afferent to the face no. 2 str. 3 bl. VI (branch 181183 ) at the horizon level. 480, the air flow increased from $8.19 \mathrm{~m} 3 / \mathrm{s}$ to $8.72 \mathrm{~m} 3 / \mathrm{s}$.

- On the exhaust circuit of the exhaust air afferent to the face no. 4 str. 3 bl. VI (branch 9089), air flow at the horizon level. 360 decreased from $5.18 \mathrm{~m} 3 / \mathrm{s}$ to $4.02 \mathrm{~m} 3 / \mathrm{s}$.

- On the face evacuation circuit no. 0 page $3 \mathrm{bl}$. VIII elevation $376 \mathrm{~m}$, respectively no. 0 str. 3 bl. VIII elevation $386 \mathrm{~m}$ (branches 249-208; 152-153), the air flows have changed insignificantly.

- At the mine level (branches 240-242 and 235-237 respectively) the flows remained practically the same.

\subsection{The situation in which the silo from the chip is empty and the door from the silo-chip connection gallery is open, respectively the collector silo oriz.360 is empty;}

Modeling no. 4 - the situation in which the silo from the chip is empty and the door from the silo-chip connection gallery is open, respectively the silo collector oriz. 360 is empty .

In order to carry out this modeling, we started from the modeling stage no. 1, in which the connection from the evacuation of the face no. 4 pp. 3 pp. VI oriz. 360 to the successor Teresa Horiz. 420 was closed.

Also, the resistance on the skip follower (branch 14-15) was reduced, simulating the skipempty silo situation. The vent door on the skip connection gallery - the upper part of the suite (branch 8-15) has been removed. At the same time, the resistance of the rice collecting silo was reduced. 360 (branch 46-48), simulating the situation of the silo collector - empty.The changes made in this modeling are shown in fig. 4.

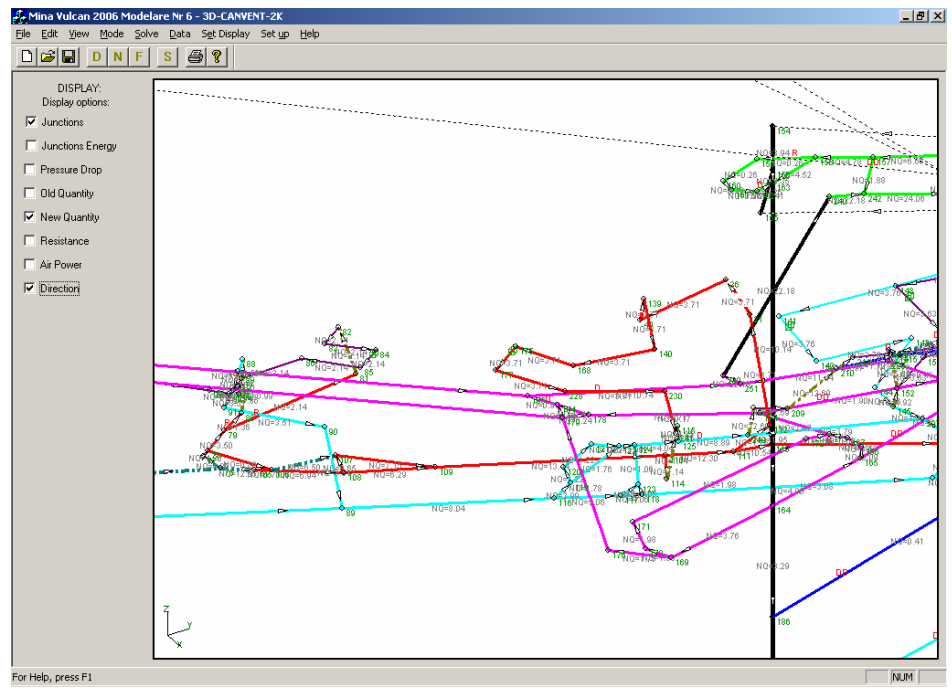

Fig. 4 Modeling no. 4

Compared to the current situation, the following results were obtained:

- The air flow on the fresh air supply circuit at the horizon level. 360, branches 22-23; 15-24;

$30-31$; 193-194 increased from $33.91 \mathrm{~m} 3 / \mathrm{s}$ to $34.85 \mathrm{~m} 3 / \mathrm{s}$. 
- The air flow on the connecting suite (branch 44-45) decreased from $1.8 \mathrm{~m} 3$ / s to $0.92 \mathrm{~m} 3$ / S.

- The air flow from the connection gallery (branch 8-15) increased from $2.18 \mathrm{~m} 3 / \mathrm{s}$ to 3.68 $\mathrm{m} 3 / \mathrm{s}$.

- The air flow at the level of the front abattoir with undermined coal bench no. 2 str. 3 bl. VI was insignificantly modified.

- The air flow on the inclined ventilation plane 360 - 315 increased from $16.03 \mathrm{~m} 3 / \mathrm{s}$ to 17.09 $\mathrm{m} 3 / \mathrm{s}$.

- The air flow at the level of the front abattoir with undermined coal bench no. 4 pp. 3 pp. VI increased from $2.1 \mathrm{~m} 3 / \mathrm{s}$ to $2.8 \mathrm{~m} 3 / \mathrm{s}$.

- Air flow at the level of face no. 0 page $3 \mathrm{bl}$. VIII elevation $376 \mathrm{~m}$ respectively no. 0 str. 3 bl. VIII elevation $386 \mathrm{~m}$ increased insignificantly.

- On the exhaust circuit of the exhaust air afferent to the face no. 2 str. 3 bl. VI (branch 181183 ) at the horizon level. 480, the air flow increased from $8.19 \mathrm{~m} 3 / \mathrm{s}$ to $8.79 \mathrm{~m} 3 / \mathrm{s}$.

- On the exhaust circuit of the exhaust air afferent to the face no. 4 str. 3 bl. VI (branch 9089), air flow at the horizon level. 360 decreased from $5.18 \mathrm{~m} 3 / \mathrm{s}$ to $4.05 \mathrm{~m} 3 / \mathrm{s}$.

- On the face evacuation circuit no. 0 page $3 \mathrm{bl}$. VIII elevation $376 \mathrm{~m}$, respectively no. 0 str. 3 bl. VIII elevation $386 \mathrm{~m}$ (branches 249-208; 152-153), the air flows have changed insignificantly.

- At the mine level (branches 240-242 and 235-237 respectively) the flows remained practically the same.

\subsection{The situation in which the silo from the chip is full and the door from the silo-chip connection gallery is closed, respectively the collector silo oriz.360 is full;}

Modeling no. 5 - the situation in which the silo from the chip is full and the door from the silo-chip connection gallery is closed, respectively the silo collector oriz. 360 is full .

In order to perform this modeling, modeling no. 1.

Also, the resistances on the chip silo (branch 8-15) were increased in order to simulate the chipfull silo situation, respectively on the rice silo. 360 (branch 46-48) to simulate the collector silo situation - full.

The changes made in this modeling are shown in fig. 5.

Compared to the current situation, the following results were obtained:

- The air flow on the fresh air supply circuit at the horizon level. 360, branches 22-23; 15-24; 30 $31 ; 193-194$ increased from $33.91 \mathrm{~m} 3 / \mathrm{s}$ to $34.33 \mathrm{~m} 3 / \mathrm{s}$.

- The air flow on the connecting suite (branch 44-45) increased from $1.8 \mathrm{~m} 3 / \mathrm{s}$ to $2.03 \mathrm{~m} 3 / \mathrm{s}$.

- The air flow from the connection gallery (branch 8-15) was reduced from $2.18 \mathrm{~m} 3 / \mathrm{s}$ to $1.98 \mathrm{~m} 3$ /s.

- The air flow at the level of the front abattoir with undermined coal bench no. 2 str. 3 bl. VI was insignificantly modified.

- The air flow on the inclined plane access base well schip (branch 34-22) increased from $3.19 \mathrm{~m} 3 / \mathrm{s}$ to $4.34 \mathrm{~m} 3 / \mathrm{s}$.

- The air flow at the level of the front abattoir with undermined coal bench no. 4 pp. 3 pp. VI increased from $2.1 \mathrm{~m} 3 / \mathrm{s}$ to $2.79 \mathrm{~m} 3 / \mathrm{s}$.

- Air flows at the level of face no. 0 page 3 bl. VIII elevation $376 \mathrm{~m}$ respectively no. 0 str. 3 bl. VIII elevation $386 \mathrm{~m}$ increased insignificantly.

- On the exhaust circuit of the exhaust air afferent to the face no. 2 str. 3 bl. VI (branch 181183 ) at the horizon level. 480, the air flow increased from $8.19 \mathrm{~m} 3 / \mathrm{s}$ to $8.73 \mathrm{~m} 3 / \mathrm{s}$.

- On the exhaust circuit of the exhaust air afferent to the face no. 4 str. 3 bl. VI (branch 9089), air flow at the horizon level. 360 decreased from $5.18 \mathrm{~m} 3 / \mathrm{s}$ to $4.0 \mathrm{~m} 3 / \mathrm{s}$. 
- On the face evacuation circuit no. 0 page $3 \mathrm{bl}$. VIII elevation $376 \mathrm{~m}$, respectively no. 0 str. 3 bl. VIII elevation $386 \mathrm{~m}$ (branches 249-208; 152-153), the air flows have changed insignificantly.

- At the mine level (branches 240-242 and 235-237 respectively) the flows remained practically the same.

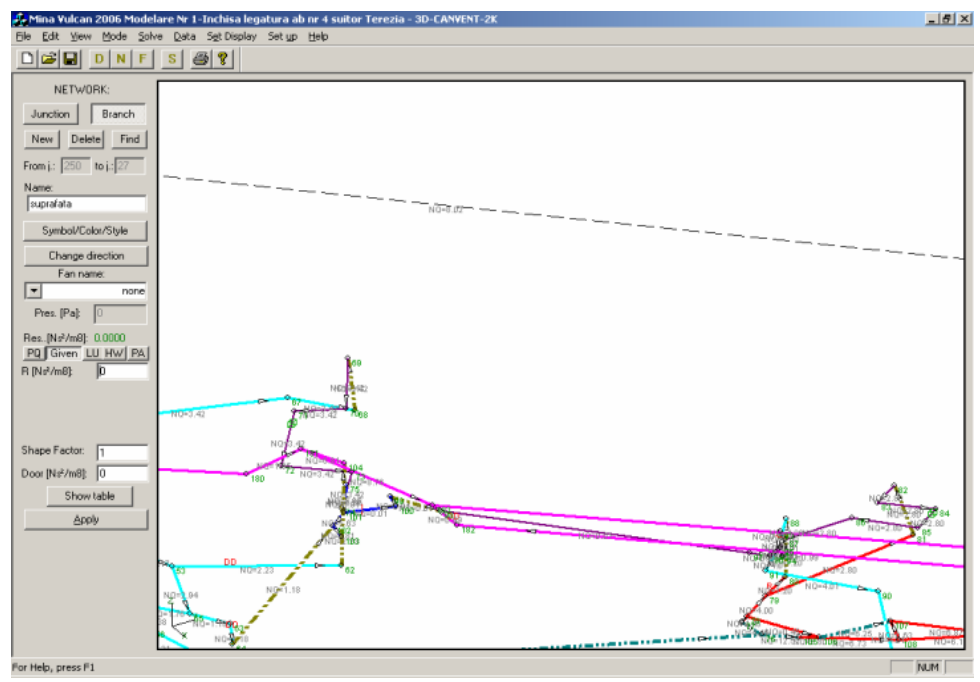

Fig. 5 Modeling no. 5

\section{Conclusions}

Solving ventilation networks with the help of computing technology is a huge step forward, which allows optimizing ventilation control and real-time visualization of network changes.

The exemplary ventilation network belongs to EM Vulcan and includes 4 wells, 3 ventilation suites, 4 horizons and a multitude of underground mining works (transversal, directional, diagonal galleries, inclined planes, connecting suites and face).

The ventilation network of the Vulcan mine was completed with the help of the CANVENT specialized program of Canadian origin, and required 10 main steps to achieve this goal.

The application of the CANVENT program allowed the realization of five simulations in the ventilation network of Vulcan mine and which represent changes that may occur in the ventilation system.

The technique of solving the ventilation network with the help of the calculation technique, allows the modeling and solving of the ventilation networks as well as any simulations of some modifications that can appear in the ventilation system regardless of its complexity.

\section{References}

[1] Boanta C.- Establishing the gas dynamics at the level of a complex ventilation network (INSEMEX Publishing House, Petroșani, 2020).

[2] Cioclea D., s.a., Solving the ventilation network based on depressiometric measurements in order to establish air flows, depressions, aerodynamic resistance, on jobs within E.M. Vulcan, (INCD INSEMEX, Petroșani, 2006) 
[3] Boanta C., Tomescu C. , s.a. - Analysis of the complex ventilation network of the Vulcan Mine with the help of the 3D Canvent and Ventsim Visual Advanced programs (INSEMEX Publishing House, Petroșani 2020).

[4] CANVENT - Mining and Minerals Sciences Laboratories Underground Mine Environment and Ventilation, User Manual - 3D program - CANVENT - $2 K$.

[5] Boantă, C., - Establishing the characteristic curves and functional parameters related to the fans at the main ventilation station Put 10 Karollus within E. M. Vulcan ,( INCD INSEMEX study, Petrosani, 2011).

[6] Băltăreţu R., Teodorescu C,- Ventilation and Occupational Safety in Mines , (Didactical and Pedagogical Publishing House, Bucharest, 1971).

[7] Teodorescu C., Gontean Z., Neag I., - Mining Ventilation ,( Didactical and Pedagogical Publishing House, Bucharest,1980).

[8] Patterson, A. M., - The Mine Ventilation Practitioner's(DATA BOOCK, M.V.S. of South Africa, 1992).

[9] Gherghe, I., Boantă C., - Aerodynamics of the exploited space - General technical aspects, Vol. I. (INSEMEX Publishing House, Petroşani, 2018).

[10]Radoi F., Boantă C., - Aerodynamics of the exploited space - General technical aspects, Vol. II. (INSEMEX Publishing House, Petroşani, 2018) .

[11] Matei I., Moraru R., Environmental engineering and underground ventilation,( Bucharest Technical Publishing House, 2000). 